J Head Trauma Rehabil. 2019 ; 34(4): E1-E10. doi:10.1097/HTR.0000000000000465.

\title{
Prevalence of Medical and Psychiatric Comorbidities Following Traumatic Brain Injury
}

Flora M. Hammond, MD, John D. Corrigan, PhD, Jessica M. Ketchum, PhD, James F. Malec, PhD, Kristen Dams-O'Conner, PhD, Tessa Hart, PhD, Thomas A. Novack, PhD, Jennifer Bogner, PhD, Marie N. Dahdah, PhD, and Gale G. Whiteneck, PhD Indiana University School of Medicine, Indianapolis

\section{Abstract}

Objective: To examine the prevalence of selected medical and psychiatric comorbidities that existed prior to, or up to 10 years following, traumatic brain injury (TBI) requiring acute rehabilitation.

Design: Retrospective cohort.

Setting: Six TBI Model Systems centers.

Participants: 404 participants in the TBI Model System National Database who experienced TBI 10 years prior.

Interventions: Not applicable.

Main Outcome Measure: Self-reported medical and psychiatric comorbidities and the onset time of each endorsed comorbidity.

Results: At 10 years post-injury, the most common comorbidities developing post-injury, in order, were: back pain, depression, hypertension, anxiety, fractures, high blood cholesterol, sleep disorders, panic attacks, osteoarthritis, and diabetes. Comparing those 50 years and older to those less than 50 years, diabetes $(\mathrm{OR}=3.54 ; p=0.0016)$, high blood cholesterol $(\mathrm{OR}=2.04 ; p=$ $0.0092)$, osteoarthritis ( $\mathrm{OR}=2.02 ; p=0.0454)$, and hypertension $(\mathrm{OR}=1.84 ; p=0.0175)$ were significantly more prevalent in the older cohort while panic attacks $(\mathrm{OR}=0.33 ; p=0.0022)$ were significantly more prevalent in the younger cohort. No significant differences in prevalence rates between the older and younger cohorts were found for back pain, depression, anxiety, fractures, or sleep disorders.

Conclusions: People with moderate-severe TBI experience other medical and mental health comorbidities during the long-term course of recovery and life after injury. The findings can inform further investigation into comorbidities associated with TBI and the role of medical care, surveillance, prevention, lifestyle, and healthy behaviors in potentially modifying their presence and/or prevalence over the life span.

Corresponding Author: Flora M. Hammond, MD, Indiana University School of Medicine, 4141 Shore Dr, Indianapolis, IN 46254 (flora.hammond@rhin.com).

The authors declare no conflict of interest. 


\section{Keywords}

prevalence; traumatic brain injury; rehabilitation; outcomes; medical conditions; comorbidities

\section{Introduction}

A growing body of evidence suggests that individuals who survive a traumatic brain injury (TBI) are at elevated risk for long-term chronic health conditions. ${ }^{1-3}$ Persons who experience TBI may have one or more pre-existing medical comorbidities at the time of injury; some evidence suggests premorbid health problems (such as alcohol use and depression) can be a risk factor for TBI, particularly among older adults. ${ }^{4-9}$ Other medical conditions may occur simultaneously with TBI, such as orthopedic trauma, or develop afterward as a direct consequence of the TBI, such as epilepsy. Still other medical comorbidities may begin months or years following injury, and their associations with the TBI may be difficult to distinguish from age-related health changes. Health comorbidities, regardless of time of onset, can further complicate recovery from TBI and long-term health maintenance, increase health care costs, and shorten life expectancy. ${ }^{10}$

Comorbidities strongly associated with TBI include chronic pain, ${ }^{11}$ headaches ${ }^{12-14}$ neuroendocrine dysfunction, ${ }^{15,16}$ fatigue or sleep disturbance including insomnia, ${ }^{17}$ incontinence or other urinary disturbance, ${ }^{18}$ new onset stroke, ${ }^{19}$ and posttraumatic seizures or epilepsy. ${ }^{20}$ In fact, in comparison to uninjured control groups, studies have suggested that individuals with TBI have more than twice the rates of pain, ${ }^{21}$ growth hormone deficiency, ${ }^{22}$ insomnia and fatigue, ${ }^{23}$ new onset stroke, ${ }^{19}$ urinary incontinence,,${ }^{24}$ and epilepsy. ${ }^{25}$ A review of published data was convened by the National Academy of Medicine to assess the association between TBI and long-term health in civilian or military populations, spanning all injury mechanisms and severities. ${ }^{26,27}$ Sufficient evidence was found that moderatesevere TBI is associated with depression, aggression, psychosis, endocrine dysfunction, Alzheimer-type dementia, and parkinsonism emerging years after injury, as well as premature death. Moderate-severe TBI and open or penetrating TBI was found to be a cause of unprovoked seizures. Many studies investigating TBI and dementia have revealed that those with a history of TBI compared to those without TBI history tended to have significantly higher rates of diabetes, hypertension, myocardial infarction, cerebrovascular disease, peripheral vascular disease, chronic pulmonary disease, renal disease, psychiatric diagnoses, and substance use disorders, and they demonstrate slower recovery following TBI. ${ }^{9,28-30}$

Individuals with moderate-severe TBI may also be at ongoing risk of rehospitalization and premature death. Causes of rehospitalization and mortality vary over time post-injury. Longitudinal modeling of rehospitalization following moderate-severe TBI suggests rehospitalization risk begins to increase around 5 years post-injury. ${ }^{31}$ Common reasons for rehospitalization after TBI include infectious, neurological, neurosurgical, traumatic, psychiatric events, and orthopedic disorders, as well as medical reasons typical for the general population. ${ }^{32-34}$ People with moderate-severe TBI are at risk of the same comorbidities as the general population while also at uniquely higher risk for death due to 
seizure, accidental poisoning, infection (aspiration pneumonia, pneumonia, septicemia), respiratory disorder, suicide, homicide, mental/behavioral disorder, nervous system conditions, falls, vehicular collisions, and other external causes of injury and poisoning. ${ }^{10}$

Previous studies have investigated cohorts with diverse characteristics, making rates of comorbidities difficult to compare across samples. Moreover, most prior studies have been cross-sectional, leaving it unknown whether the medical comorbidities pre- or post-dated the TBI. Therefore, the prevalence rates of comorbidities that co-occur with TBI remain unclear.

Individuals living with the effects of TBI face multiple challenges to effective health management, including cognitive impairment, limited financial resources, reduced participation in society, and variable access to specialized care, ${ }^{35-38}$ making it particularly difficult to manage multiple chronic health comorbidities. Whether those health problems are pre-existing or arise after injury, the intersection of TBI-related impairments with chronic health problems can have a mutually exacerbating effect on overall health and life quality. Yet, it is important to know more about the nature and timing of the onset of medical comorbidities among individuals with TBI to inform the development of optimal health management and prevention strategies. The purpose of this study is to assess the prevalence of selected medical and psychiatric comorbidities, as well as the timing of onset in relation to the index TBI, using a cohort of the TBI Model Systems (TBIMS) longitudinal National Database participants who had survived to 10 years post-injury. The longitudinal nature of this study with a focus on timing of onset and inclusion of both medical and psychiatric comorbidities offers a unique contribution to the literature. Prior studies have generally examined the associations between TBI and one or two other medical or psychiatric conditions among patients seen in a single center. This study builds on this prior research by examining 44 medical and psychiatric conditions that have been previously shown or hypothesized to be associated with TBI in a large sample drawn from multiple centers representing diverse regions of the continental United States.

\section{Methods}

\section{Participants}

Participants included individuals within the TBIMS National Database at six TBIMS centers: The Ohio State University (Columbus, OH); University of Texas Southwest Medical school/Baylor Scott and White Institute for Rehabilitation (Dallas, TX); Craig Hospital (Englewood, CO); Icahn School of Medicine at Mount Sinai (New York, NY); Moss Rehabilitation Research Institute (Elkins Park, PA); University of Alabama at Birmingham (Birmingham, AL). Each center received approval for human subjects research from their respective Institutional Review Boards. The TBIMS National Database enrollment criteria include: age at least 16 years at time of injury; moderate-severe TBI [defined as posttraumatic amnesia greater than 24 hours, trauma-related intracranial neuroimaging abnormalities, loss of consciousness exceeding 30 minutes, or GCS in the emergency department of less than 13]; and received acute care hospitalization within 72 hours followed by inpatient rehabilitation in designated TBIMS facilities. An additional inclusion criteria for the current study was that participants needed to be eligible for their 10-year follow-up window between 7/1/2013 and 9/30/2017 and had FIM ${ }^{\mathrm{TM}}$ data collected during at least 2 of 
the three prior follow-up interviews (at 1,2, and 5-years post-injury); the FIM data criterion was used for a different investigation with the same cohort. Eligible participants were consecutively enrolled in this study when they were contacted for their 10-year TBIMS telephone follow-up interview.

\section{Outcome Measures}

\section{Medical and Mental Health Comorbidities Interview (MMHCl).-The MMHCI}

interview recorded the presence of 44 medical and mental health comorbidities during an individual's lifetime, and if present, whether the diagnosis occurred before or after the TBI that qualified them for TBIMS participation. The interview was modeled after national health surveys, using the National Health and Nutrition Examination Survey (NHANES) for the medical comorbidities and the National Comorbidity Survey Replication (NCS-R) for the mental health comorbidities. ${ }^{39}$ All items used the stem "Has a doctor ever told you that you had ...". The national survey questions were utilized given their widespread use in the general population. The 44 comorbidities were chosen by the investigators based on those conditions collected through the two national survey tools; investigators' clinical experience in TBI; and information gleamed through prior TBI research suggesting a higher than normal rate after TBI, uncertainty about the relationship with TBI, or the possibility to screen and/or treat the condition with potential to positively impact life after TBI.

\section{Procedures}

Participants were asked the MMCHI questions after the standard 10-year follow-up interview. For MMHCI comorbidities endorsed by the respondent, participants were asked whether the comorbidity was diagnosed before, at the same time, or after their TBI (the index TBI that occurred 10 years prior to this interview). Per TBIMS follow-up interview protocols, information was obtained from the best source, either the participant with TBI or a significant other. Missing data on the medical comorbidities ranged from 0 to $2.5 \%$ ( 0 to 10 participants).

\section{Statistical Analysis}

All data was analyzed using SAS v.9.4 $4^{40}$ assuming a 5\% level of significance unless otherwise noted. The prevalence of each of the 44 medical comorbidities was estimated along with $95 \%$ confidence intervals (CIs). Prevalence rates for each comorbidity were estimated in three different time frames: (1) those having the comorbidity diagnosed before the index TBI, (2) those having the comorbidity diagnosed at either the same time or after their TBI, and (3) those having the comorbidity diagnosed ever in their lifetime (before, same time, or after their TBI). Each of these ways of defining onset corresponds with potentially important parameters for informing proactive medical management in the years after serious TBI. Finally, the percentages and $95 \%$ CIs of the 10 most prevalent medical comorbidities occurring at the same time or after TBI were estimated for participants in two age groups: those with 10-year post-injury follow-ups occurring before age 50, and those with 10 year follow-up at age 50 or older. Logistic regression models were used to compare prevalence rates between the older and younger cohorts. Prior publications have utilized varied age cut-offs in the comparison of younger to older age cohorts in TBI, with the most 
common cut-points being 50, 60, and 65 years. ${ }^{41}$ Fifty years was chosen for the present study based on literature suggesting this age cohort has higher rates of comorbidities and complications, including deterioration in cognitive and emotional function. ${ }^{42-47}$

\section{Results}

Data were collected from 404 participants. Characteristics of the sample are shown in Table 1.

The estimated prevalence rates before TBI, at the same time or after TBI, and ever (before, same time or after TBI) for the medical and psychiatric comorbidities and the associated 95\% confidence intervals are summarized in Table 2 . The most common comorbidities occurring ever in participants' lifetimes, in order, were hypertension, back pain, depression, high blood cholesterol, anxiety, and fractures (hip/wrist/spine) (see Table 3). Each of these comorbidities affected approximately one-fourth to one-third of the cohort. There was a significant drop in prevalence from fractures $(\sim 23 \%)$ to the next most common, osteoarthritis, which affected less than $15 \%$.

The 10 most common comorbidities developing at the same time or after injury largely reflected those most common in one's lifetime. One exception was alcoholism, which was among the 10 most prevalent comorbidities before TBI, but dropped off the list at the same time or after TBI. It was instead replaced by diabetes at the time of/after TBI. For hypertension, high blood cholesterol, depression and anxiety, more than half of participants who had ever had the comorbidities developed them at the same time or post-injury; twothirds or more of those with sleep disorders, diabetes and panic attacks were diagnosed at the same time or post-injury. The only comorbidity diagnosed in more than $10 \%$ of cases before the TBI was hypertension; comorbidities diagnosed before the TBI in 5-10\% of the cases were hay fever, high blood cholesterol, alcoholism, back pain, depression, attentiondeficit (hyperactivity) disorder, and anxiety.

Table 4 displays the 10 most prevalent medical and psychiatric comorbidities diagnosed at the same time or after the TBI separately for the younger and older participants. Odds ratios were computed to express the relative magnitude of the prevalence of comorbidities in the older group compared to the prevalence in the younger group. Diabetes $(\mathrm{OR}=3.54 ; p=$ $0.0016)$, high blood cholesterol ( $\mathrm{OR}=2.04 ; p=0.0092)$, osteoarthritis $(\mathrm{OR}=2.02 ; p=$ 0.0454 ), and hypertension ( $\mathrm{OR}=1.84 ; p=0.0175$ ) were significantly more prevalent in the older cohort, while panic attacks $(\mathrm{OR}=0.33 ; \mathrm{p}=0.0022)$ were significantly more prevalent in the younger cohort. There were no significant differences in prevalence rates between the older and younger cohorts for back pain, depression, anxiety, fractures, or sleep disorders.

\section{Discussion}

This study represents an initial attempt to characterize the medical and psychiatric comorbidities experienced by people who sustained TBI severe enough to warrant inpatient rehabilitation, and who have survived for at least 10 years. One-fifth of our sample reported a diagnosis of anxiety, depression, hypertension, or back pain. Other comorbidities with high prevalence included high cholesterol, fractures, sleep disorder, and panic attacks. The 
presence of all of these comorbidities doubled from before TBI to time of TBI or after. Diagnoses of alcoholism did not substantially increase after TBI.

While disease onset post-injury does not indicate a causal relationship with TBI (i.e., 10 years of aging had occurred at the time of assessment), there is reason to suspect that some later-developing comorbidities are causally related to the injury. TBI not only disrupts central nervous system (CNS) function, but can potentially have short and long-term effects on the autonomic nervous system (ANS) ${ }^{48-52}$ as well. Chronic inflammation, insulin resistance, and metabolic syndrome are consequences of CNS and ANS dysfunction that can lead to the development of chronic disease. ${ }^{53-57}$ Disruption of ANS (in addition to the CNS) is also associated with the dysregulation of emotions and behavior, ${ }^{58,59}$ which may be sufficiently severe to be diagnosed as a psychiatric disorder. Moreover, TBI-related cognitive and behavioral symptoms may pose challenges for health self-management such that a TBI influences medical health through non-biological pathways. Regardless of causality, however, interventions currently known to help prevent the most likely comorbidities should be recommended, including those targeting exercise, diet, and stress management, as well as treatments supporting the maintenance of meaningful and pleasurable activity in the community.

The prevalence rates for comorbidities first occurring after TBI are essentially incidence rates over the decade between injury and the 10-year follow-up data collection. Four of the 10 most frequent comorbidities occurring in the first decade after the TBI were significantly more frequent in older individuals than younger individuals. During the decade after TBI, the new onset diabetes rate was $4.3 \%$ for the younger group (less than age 40 at the start of the decade and less than age 50 at the end of the decade) compared to $13.6 \%$ for the older group (age 40 and older at the start of the decade and age 50 and older at the end of the decade). This is only slightly higher than new onset diabetes in the general population (3.1\% per decade for age 18-44, 10.9\% per decade for age 45-64, and 9.6\% per decade for age 65 and over). ${ }^{60}$ Since the TBI and general population rates both increase sharply with age but do not differ substantially from each other, diabetes seems to be more strongly associated with aging than with TBI.

New onset hypertension, high blood cholesterol, and osteoarthritis all occurred about twice as frequently in the older group as in the younger group, indicating they too may be associated with age. In 2013-2014, 55.9\% of community-dwelling adults aged 65 and older in the United States reported having a diagnosis of hypertension, 29.4\% reported heart disease, $20.8 \%$ reported diabetes, and $49 \%$ reported having arthritis. ${ }^{61,62}$ Data from the National Health and Nutrition Examination Survey indicate that $70 \%$ of older adults have hypertension, compared to only $32 \%$ for adults aged $40-59$ years. ${ }^{63}$ Given the association of these conditions with age in the general population combined with this study's findings of similar age relationships with these conditions may suggest the rates observed herein are reflective of aging more so than TBI-related health changes. Because the effects of a TBI are overlaid upon the effects of aging, their relative contributions cannot be readily disentangled.

On the other hand, new onset panic attacks were three times more frequent in the decade after TBI in the younger group than in the older group. This finding highlights the 
importance of screening for depression and anxiety disorders and specifically for panic attacks after TBI, particularly among relatively younger TBI survivors, with referral of positive cases for further evaluation and treatment. No significant age effects were identified for back pain, depression, anxiety, fractures, or sleep disorders, suggesting a potentially stronger association with TBI than aging. The absolute and relative magnitude of these comorbidity rates provides initial insight into the association these comorbidities have with the combination of TBI and aging.

Our findings highlight the need for careful screening for comorbid comorbidities in survivors of moderate-severe TBI. Psychiatric comorbidities including anxiety and depression are strongly comorbid with TBI, as suggested by prior TBI Model System research, ${ }^{64,65}$ and warrant special attention for prevention as well as detection and treatment. With regard to medical comorbidities, people with moderate-severe TBI frequently have long-term cognitive dysfunction that may interfere with the ability to manage those comorbidities, e.g., to take medications accurately and to arrange follow-up appointments. Healthcare providers may need to engage relatives in health management tasks and/or provide extra supports such as written information and reminders.

\section{Limitations:}

In this study, as is the case in most longitudinal studies of health conditions, the outcome required the use of self-report, raising questions of accuracy. While it was not possible to verify self-report against medical records in the current investigation, a recent study using the TBIMS cohort showed good to excellent test-retest reliability for the same questions about health conditions when readministered. ${ }^{66}$ Studies have found positive congruence of self-report and physician ratings and stability of ratings overtime, with occurrences of incongruity to be towards an individual overestimating one's health and self-report better predicting future physician ratings ${ }^{67}$ There may be other conditions common among the TBI population not represented in this study as the interview included a only subset of possible conditions. The TBIMS is comprised of specialized centers for TBI inpatient rehabilitation, and thus, our findings may not generalize to individuals with TBI who are treated at less specialized centers or who do not receive inpatient rehabilitation. It is important to note that this study does not assess for causal relationships between the TBI and the subsequent comorbidities. No control (non-injured) group was available for comparison. Comparisons to the literature on the general population are challenging for many reasons including potential population differences, and limited general population prevalence data for individuals younger than 65 years. We did not exclude participants who had previously incurred TBI, for whom some of the comorbid conditions identified as occurring prior to a TBI may have occurred after a (previous) TBI. Finally, it is important to consider that the current study only included individuals who survived at least 10 years post moderate-severe TBI, and therefore excludes those who likely experienced the most significant increases in TBI-related disease morbidity. Results from the current study and their implications for the chronic disease management needs among TBI survivors should be interpreted in this context. 


\section{Directions for future research:}

Since only individuals who received inpatient rehabilitation were included in our sample, further examination of differences in comorbidities between those who received inpatient rehabilitation and those that did not is of interest. Differences in the types of comorbidities and their prevalence between a subsample of TBI survivors with multiple TBIs prior to index injury and those with a single TBI would also be valuable, particularly if the presence of multiple TBIs served to modify the above treatment suggestions. Controlled studies that include a cohort without TBI are needed to evaluate the possibility of causal relationships between TBI and subsequent comorbidities. Of particular interest in this regard is exploration of the possible role of disruption of CNS and ANS function by TBI in the development of chronic disease through either metabolic and/or behavioral pathways. Future research is also needed to evaluate the potential positive impact of a chronic disease management approach to TBI that includes surveillance, prevention and treatment of medical and psychiatric comorbidities on community re-integration and satisfaction with life in the long term.

\section{Conclusion}

Individuals recovering from a moderate-severe TBI are at risk for medical and mental health comorbidities during long-term course of recovery and life after injury. The findings can inform further investigation into comorbidities associated with TBI and the role of medical care, surveillance, prevention, lifestyle and healthy behaviors in potentially modifying their presence and/or prevalence over TBI survivors' life span.

\section{Acknowledgements:}

The contents of this publication were developed under grants from the National Institute on Disability, Independent Living, and Rehabilitation Research: Indiana University School of Medicine/Rehabilitation Hospital of Indiana (Grant \#90DP0036), Icahn School of Medicine at Mount Sinai (Grant \#90DP0038), Rocky Mountain Regional Brain Injury System (Grant \#90DP0034), Ohio State University (Grant \#90DP0040), University of Alabama at Birmingham (Grant \#90DP0044), Traumatic Brain Injury Model Systems National Data and Statistical Center (Grant \#90DP0013 and \#90DP0084), Moss TBI Model System (Grant \#90DP0037), North Texas TBI Model System (Grant \# 90DP0045) and from the National Institutes of Health National Center for Medical Rehabilitation Research (NICHD; K01HD074651). NIDILRR is a Center within the Administration for Community Living (ACL), Department of Health and Human Services (HHS). The contents of this publication do not necessarily represent the policy of NIDILRR, ACL, HHS, and you should not assume endorsement by the Federal Government.

\section{References}

1. Masel BE. The Chronic Consequences of Neurotrauma. J Neurotrauma. 2015 12 1;32(23):1833. [PubMed: 26629808]

2. Masel BE, DeWitt DS. Traumatic Brain Injury: A Disease Process, Not an Event. J Neurotrauma. 2010 8;27(8):1529-40. [PubMed: 20504161]

3. Corrigan JD, Hammond FM. Traumatic Brain Injury as a Chronic Health Condition. Arch Phys Med Rehabil. 2013 6;94(6):1199-201. [PubMed: 23402722]

4. Dams-O’Conner K, Gibbons LE, Landau A, Larson EB, Crane PK. Health Problems Preceded Traumatic Brain Injury in Older Adults. J Am Geriatr Soc. 2016 4;64(4):844-8. [PubMed: 26925541]

5. Bombardier CH, Rimmele CT, Zintel H. The Magnitude and Correlates of Alcohol and Drug Use Before Traumatic Brain Injury. Arch Phys Med Rehabil. 2002 83(12):1765-73. [PubMed: 12474184] 
6. Burke JF, Stulc JL, Skolarus LE, Sears ED, Zahuranec DB, Morgenstern LB. Traumatic brain injury may be an independent risk factor for stroke. Neurology. 2013;81(1), 33-39. [PubMed: 23803315]

7. Mosenthal AC, Livingston DH, Lavery RF, Knudson MM, Lee S, Morabito D, Manley GT, Nathens A, Jurkovich G, Hoyt DB, Coimbra R. The Effect of Age on Functional Outcome in Mild Traumatic Brain Injury: 6-month Report of a Prospective Multicenter Trial. J Trauma. 2004;56(5):1042-48. [PubMed: 15179244]

8. Pasquale MD, Cipolle MD, Masiado T, Wasser T. Utilization of National Trauma Data Bank (NTDB) to determine Impact of Age and Comorbidity on Mortality Rates in Isolated Head Injury. Crit Care Med. 2005;33(S12):A40.

9. Thompson HJ, McCormick WC, Kagan SH. Traumatic brain injury in older adults: epidemiology, outcomes, and future implications. J Am Geriatr Soc. 2006;54(10):1590-1595. [PubMed: 17038079]

10. Harrison-Felix C, Pretz C, Hammond FM, Cuthbert JP, Bell J, Corrigan J, Miller AC, HaarbauerKrupa J: Life Expectancy after Inpatient Rehabilitation for Traumatic Brain Injury in the United States. J Neurotrauma. 2015;32(23):1893-901. [PubMed: 25057965]

11. Finley EP, Bollinger M, Noël PH, Amuan ME, Copeland LA, Pugh JA, Dassori A, Palmer R, Bryan C, Pugh MJ. A national cohort study of the association between the polytrauma clinical triad and suicide-related behavior among US Veterans who served in Iraq and Afghanistan. Am J Public Health. 2015;105(2):380-7. [PubMed: 25033126]

12. Walker WC, Seel RT, Curtiss G, Warden DL. Headache after moderate and severe traumatic brain injury: a longitudinal analysis. Arch Phys Med Rehabil. 2005;86(9):1793-800. [PubMed: 16181945]

13. Lucas S, Hoffman JM, Bell KR, Walker W, Dikmen S. Characterization of headache after traumatic brain injury. Cephalalgia. 2012;32(8):600-6. [PubMed: 22623761]

14. Stacey A, Lucas S, Dikmen S, Temkin N, Bell D, Brown A, Brunner R, Diaz-Arrastia R, Watanabe TK, Weintraub A, Hoffman J. Natural history of headache five years after traumatic brain injury. Journal of Neurotrauma. 2017;34:1558-1564. [PubMed: 27927072]

15. Tanriverdi F, Ulutabanca H, Unluhizarci K, Selcuklu A, Casanueva FF, Kelestimur F. Three years prospective investigation of anterior pituitary function after traumatic brain injury: a pilot study. Clin Endocrinol. 2008;68(4):573-9.

16. Agha A, Thornton E, O'Kelly P, Tormey W, Phillips J, Thompson CJ. Posterior pituitary dysfunction after traumatic brain injury. J Clin Endocrinol Metab 2004;89(12):5987-92. [PubMed: 15579748]

17. Jain A, Mittal RS, Sharma A, Sharma A, Gupta ID. Study of insomnia and associated factors in traumatic brain injury. Asian J Psychiatr. 2014;8:99-103. [PubMed: 24655637]

18. Moiyadi AV1, Devi BI, Nair KP. Urinary disturbances following traumatic brain injury: clinical and urodynamic evaluation. NeuroRehabil. 2007;22(2):93-8.

19. Liao CC, Chou YC, Yeh CC, Hu CJ, Chiu WT, Chen TL. Stroke Risk and Outcomes in Patients with Traumatic Brain Injury: 2 Nationwide Studies. Mayo Clin Proc 2014;89(2):163-72. [PubMed: 24485130]

20. Pugh MJ, Orman JA, Jaramillo CA, Salinsky MC, Eapen BC, Towne AR, Amuan ME, Roman G, McNamee SD, Kent TA, McMillan KK, Hamid H, Grafman JH. The prevalence of epilepsy and association with traumatic brain injury in veterans of the Afghanistan and Iraq wars. J Head Trauma Rehabil. 2015;30(1):29-37. [PubMed: 24695268]

21. Ponsford JL, Parcell DL, Sinclair KL, Roper M, Rajaratnam SM. Changes in Sleep Patterns Following Traumatic Brain Injury: A Controlled Study. Neurorehabil Neural Repair. 2013;27(7): 613-21. [PubMed: 23549523]

22. Tanriverdi F, Schneider HJ, Aimaretti G, Masel BE, Casanueva FF, Kelestimur F. Pituitary Dysfunction After Traumatic Brain Injury: A Clinical and Pathophysiological Approach. Endocrine Reviews. 2015;36(3):305-342. [PubMed: 25950715]

23. Beaulieu-Bonneau S, Morin CM. Sleepiness and Fatigue Following Traumatic Brain Injury. Sleep Medicine. 2012;13(6):598-605. [PubMed: 22425680]

24. Keller JJ, Liu SP, Lin HC. Traumatic Brain Injury Increases the Risk of Female Urinary Incontinence. Neurourology and Urodynamics. 2013;32(4): 354-358. [PubMed: 22965745] 
25. Yeh CC, Chen TL, Hu CJ, Chiu WT, Liao CC: Risk of Epilepsy after Traumatic Brain Injury: A Retrospective Population-based Cohort Study. J Neurol Neurosurg Psychiatry. 2013;84(4):441-5. [PubMed: 23117492]

26. Institute of Medicine. Gulf War and Health: Volume 7: Long-Term Consequences of Traumatic Brain Injury. Washington, DC: National Academies Press, 2009.

27. Ishibe N, Wlordarczyk RC, Fulco C. Overview of the Institute of Medicine's committee search strategy and review process for Gulf War and health: long-term consequences of traumatic brain injury. J Head Trauma Rehabil. 24:424-429, 2009. [PubMed: 19940675]

28. Barnes DE, Kaup A, Kirby KA, Byers AL, Diaz-Arrastia R, Yaffe K. Traumatic brain injury and risk of dementia in older veterans. Neurol. 2014;83(4):312-9.

29. Gardner RC, Yaffe K. Traumatic brain injury may increase risk of young onset dementia. Ann Neurol. 2014;75(3):339-41. [PubMed: 24550062]

30. Nordström P, Michaëlsson K, Gustafson Y, Nordström A. Traumatic brain injury and young onset dementia: a nationwide cohort study. Ann. Neurol 2014;75(3), 374-381. [PubMed: 24812697]

31. Dams-O’Connor K, Mellick D, Dreer LE, Hammond FM, Hoffmann J, Landau A, Zafonte R, Pretz C. Rehospitalization Over 10 Years Among Survivors of Traumatic Brain Injury Model Systems Study. J Head Trauma Rehabil. 2017;32(3):147-157. [PubMed: 28476056]

32. Hammond FM, Horn SD, Smout RJ, Seel RT, Beaulieu CL, Corrigan JD, Cullen N, Sommerfeld T, Brandstater ME: Rehospitalization During the First 9-Months Following Inpatient Rehabilitation for Traumatic Brain Injury. Arch Phys Med Rehabil. 2015;96(8Suppl3):S330-339. [PubMed: 26212407]

33. Marwitz JH, Cifu DX, Englander J, and High WM. A Multi-center Analysis of Rehospitalizations Five Years After Brain Injury. J Head Trauma Rehabil. 2001;16(4):307-317. [PubMed: 11461654]

34. Nakase-Richardson R, Tran J, Cifu D, Barnett SD, Horn L, Greenwald BD, Brunner R, Whyte J, Hammond FM, Yablon SA, Giacino JT: Do rehospitalization rates differ among injury severity levels in the NIDRR TBI Model Systems Program? Arch Phys Med Rehabil. 2013;94:1884-90; 20136 13. [PubMed: 23770278]

35. Dikmen SS, Corrigan JD, Levin HS, Machamer J, Stiers W, Weisskopf MG. Cognitive outcome following traumatic brain injury. J Head Trauma Rehabil. 2009;24(6):430-438. [PubMed: 19940676]

36. Temkin NR, Corrigan JD, Dikmen SS, Machamer J. Social functioning after traumatic brain injury. J Head Trauma Rehabil. 2009;24(6):460-467. [PubMed: 19940679]

37. Devitt R, Colantonio A, Dawson D, Teare G, Ratcliff G, Chase S. Prediction of long-term occupational performance outcomes for adults after moderate to severe traumatic brain injury. Disabil Rehabil. 2006;28(9):547-59. [PubMed: 16690584]

38. Kolakowsky-Hayner SA, Kreutzer JS, Miner KD. Validation of the service obstacles scale for the traumatic brain injury population. NeuroRehabilitation. 2000;14(3):151-158. [PubMed: 11455077]

39. National Health and Nutrition Examination Survey (NHANES). Center for Disease Control, National Center for Health Statistics https://www.cdc.gov/nchs/nhanes/index.htm Accessed 7/9/17.

40. Copyright (c) 2002-2012 by SAS Institute Inc., Cary, NC, USA.

41. Goleburn CR, Golden CJ. Traumatic Brain Injury Outcome in Older Adults: A Critical Review of the Literature. Journal of Clinical Geropsychology 2001;7(3):161-187.

42. Kumar RG, Olsen J, Juengst SB, Dams-O’Connor K, O’Neil-Pirozzi TM, Hammond FM, Wagner AK: Comorbid Conditions Among Adults 50 Years and Older with Traumatic Brain Injury: Examining Associations with Demographics, Health Care Utilization, Institutionalization and 1year Outcomes. J Head Trauma Rehabil In Press.

43. Mazzucchi A, Cattelani R, Missale G, Gugliotta M, Brianti R, Parma M. Head-injured subjects aged over 50 years: Correlation Between Variables of Trauma and Neuropsychological Follow-up. J Neurol 1992;239:256-260. [PubMed: 1607886]

44. Goldstein FC, Levin HS. Neurobehavioral Outcome of Traumatic Brain Injury in Older Adults: Initial Findings. J Head Trauma Rehabil 1995;10(1):57-73. 
45. Goldstein FC, Levin HS, Roberts VJ, Goldman WP, Kalechstein AS, Winslow M, Goldstein SJ. Neuropsychological Effects of Closed Head Injury in Older Adults: A Comparison with Alzheimer's Disease. Neuropsychology 1996;10(2):147-154.

46. Goldstein FC. Aging and Recovery. Recovery 1998;9(3):28-29.

47. Goldstein FC, Levin HS, Goldman WP, Kalechstein AD, Clark AN, Kenchan-Altonen T. Cognitive and Behavioral Sequelae of Closed Head Injury in Older Adults According to Their Significant Others. J Neuropsychiatry Clin Neurosci 1999;11:38-44. [PubMed: 9990554]

48. Keren O, Yupatov S, Radai MM, Elad-Yarum R, Faraggi D, Abboud S, Ring H, Grosswasser Z. Heart rate variability (HRV) of patients with traumatic brain injury (TBI) during the post-insult sub-acute period. Brain Inj. 2005;19(8):605-611. [PubMed: 16175814]

49. Norris PR, Ozdas A, Cao HQ, Williams AE, Harrell FE, Jenkins JM, Morris JA. Cardiac uncoupling and heart rate variability stratify ICU patients by mortality - A study of 2088 trauma patients. Brain Inj. 2006;243(6):804-814.

50. Baguley IJ, Heriseanu RE, Felmingham KL, Cameron ID. Dysautonomia and heart rate variability following severe traumatic brain injury. Brain Inj. 2006;20(4):437-444. [PubMed: 16716989]

51. Baguley IJ, Nicholls JL, Felmingham KL, Crooks J, Gurka JA, Wade LD. Dysautonomia after traumatic brain injury: A forgotten syndrome? J Neurol Neurosurg Psychiatry. 1999;67(1):39-43. [PubMed: 10369820]

52. Baguley IJ, Heriseanu RE, Nott MT, Chapman J, Sandanam J. Dysautonomia after severe traumatic brain injury: Evidence of persisting overresponsiveness to afferent stimuli. Am J Phys Med Rehabil. 2009;88(8):615-622. [PubMed: 19620826]

53. Jarczok MN, Koenig J, Li J, et al. The association of work stress and glycemic status is partially mediated by autonomic nervous system function: Cross-sectional results from the mannheim industrial cohort study (MICS). PLoS One. 2016;11(8):e0160743. [PubMed: 27532642]

54. Jarczok MN, Koenig J, Mauss D, Fischer JE, Thayer JF. Lower heart rate variability predicts increased level of C-reactive protein 4 years later in healthy, nonsmoking adults. J Intern Med. 2014;276(6):667-671. [PubMed: 25141771]

55. Jarczok MN, Li J, Mauss D, Fischer JE,Thayer JF. Heart rate variability is associated with glycemic status after controlling for components of the metabolic syndrome. Int J Cardiol.

56. Schuster AK, Fischer JE, Thayer JF, Mauss D, Jarczok MN. Decreased heart rate variability correlates to increased cardiovascular risk. Int J Cardiol. 2016;203:728-730. [PubMed: 26587729]

57. Smith JA, Das A, Ray SK, Banik NL. Role of pro-inflammatory cytokines released from microglia in neurodegenerative diseases. Brain Res Bull. 2012;87(1):10-2 [PubMed: 22024597]

58. Ramirez E, Ortega AR, Reyes Del Paso GA. Anxiety, attention, and decision making: The moderating role of heart rate variability. Int J Psychophysiol. 2015;98(3 Pt 1):490-496. [PubMed: 26555079]

59. Holzman JB, Bridgett DJ. Heart rate variability indices as bio-markers of top-down self-regulatory mechanisms: A meta-analytic review. Neurosci Biobehav Rev. 2017;74(Pt A):233-255. [PubMed: 28057463]

60. Centers for Disease Control and Prevention, National Center for Chronic Disease Prevention and Health Promotion, Division of Diabetes Translation. National Diabetes Statistics Report, 2017: Estimates of Diabetes and Its Burden in the United States. Accessed 6-10-18 at http:// www.diabetes.org/assets/pdfs/basics/cdc-statistics-report-2017.pdf

61. Thompson HJ, Dikmen S, Temkin N. Prevalence of comorbidity and its association with traumatic brain injury and outcomes in older adults. Res Gerontol Nurs. 1 2012;5(1):17-24. [PubMed: 22165997]

62. Federal Interagency Forum on Aging-Related Statistics. Older Americans 2016: Key indicators of well-being. 2016 Retrieved from Health Status: https://agingstats.gov/data.html

63. Mozaffarian D, Benjamin EJ, Go AS, Arnett DK, Blaha MJ, Cushman M, de Ferranti S, Despres JP, Fullerton HJ, Howard VJ, Huffman MD, Judd SE, Kissela BM, Lackland DT, Lichtman JH, Lisabeth LD, Liu S, Mackey RH, Matchar DB, McGuire DK, Mohler ER 3rd, Moy CS, Muntner P, Mussolino ME, Nasir K, Neumar RW, Nichol G, Palaniappan L, Pandey DK, Reeves MJ, Rodriguez CJ, Sorlie PD, Stein J, Towfighi A, Turan TN, Virani SS, Willey JZ, Woo D, Yeh RW, Turner MB, American Heart Association Statistics Committee and Stroke Statistics Subcommittee. 
Heart disease and stroke statistics--2015 update: a report from the American Heart Association. Circulation. 2015;131:e29-322. [PubMed: 25520374]

64. Hart T, Hoffman JM, Pretz C, Kennedy R, Clark AN, Brenner LA. A longitudinal study of major and minor depression following traumatic brain injury. Arch Phys Med Rehabil. 2012;93:1343-9. [PubMed: 22840833]

65. Hart T, Fann JR, Chervoneva I, Juengst SB, Rosenthal JA, Krellman JW, Dreer LE, Kroenke K. Prevalence, risk factors, and correlates of anxiety at one year after moderate to severe traumatic brain injury. Arch Phys Med Rehabil. 2016;97:701-707. [PubMed: 26707456]

66. Bogner JA, Whiteneck GG, MacDonald J, Juengst SB, Brown AW, Philippus AM, Marwitz JH, Lengenfelder J, Mellick D, Arenth P, Corrigan JD. Test-retest Reliability of Traumatic Brain Injury Outcome Measures: A Traumatic Brain Injury Model Systems study. J Head Trauma Rehabil 2017;32:E1-E16.

67. Maddox GL, Douglas EB: Self-assessment of Health. A Longitudinal Study of Elderly Subjects. J of Health and Social Behavior 1973:14(1):87-93. 
Table 1:

Summary of Sample Characteristics $(N=404)$

\begin{tabular}{|c|c|c|c|}
\hline Continuous Characteristics & $N$ & Mean (SD) & Median (IQR) \\
\hline Age at Injury (years) & 404 & $37.8(16.0)$ & $37(23-49.5)$ \\
\hline Age at 10 year FU (years) & 404 & $47.9(15.9)$ & $48(33-59)$ \\
\hline Glasgow Coma Scale & 304 & $9.5(4.7)$ & $9(5-14)$ \\
\hline FIM Motor Discharge & 403 & $69.2(18.1)$ & $72(60-83)$ \\
\hline FIM Cognitive at Discharge & 403 & $23.5(6.6)$ & $25(20-28)$ \\
\hline Post Traumatic Amnesia (days) ${ }^{\dagger}$ & 388 & $31.7(31.7)$ & $23(10.5-44)$ \\
\hline Time to Follow Commands (days) ${ }^{\dagger}$ & 400 & $10.5(20.2)$ & $3(0.5-12)$ \\
\hline Rehabilitation Length of Stay (days) ${ }^{\dagger}$ & 404 & $26.1(19.7)$ & $21(13-33)$ \\
\hline Nominal Characteristics & $N$ & Count (Percent) & \\
\hline Sex & 404 & & \\
\hline Female & & $97(24.0 \%)$ & \\
\hline Male & & $307(76.0 \%)$ & \\
\hline Race & 404 & & \\
\hline White & & $280(69.3 \%)$ & \\
\hline Black & & $78(19.3 \%)$ & \\
\hline Hispanic & & $31(7.7 \%)$ & \\
\hline Other & & $15(3.7 \%)$ & \\
\hline Marital Status at injury & 404 & & \\
\hline Married & & $141(34.9 \%)$ & \\
\hline Not Married & & $263(65.1 \%)$ & \\
\hline Education Level & 404 & & \\
\hline Less than High School & & $138(34.2 \%)$ & \\
\hline High School & & $109(27.0 \%)$ & \\
\hline Some College & & $91(22.5 \%)$ & \\
\hline College & & $66(16.3 \%)$ & \\
\hline Employment at injury & 404 & & \\
\hline Employed & & $277(68.6 \%)$ & \\
\hline Not Employed & & $127(31.4 \%)$ & \\
\hline
\end{tabular}

$\mathrm{IQR}=$ interquartile range, $\mathrm{SD}=$ standard deviation, $\mathrm{FU}=$ follow-up

${ }^{\dagger}$ Distributions markedly skewed thus median and IQR are more appropriate measures of center and spread than mean and SD 


\section{롱 \\ 골}

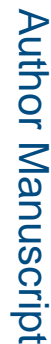

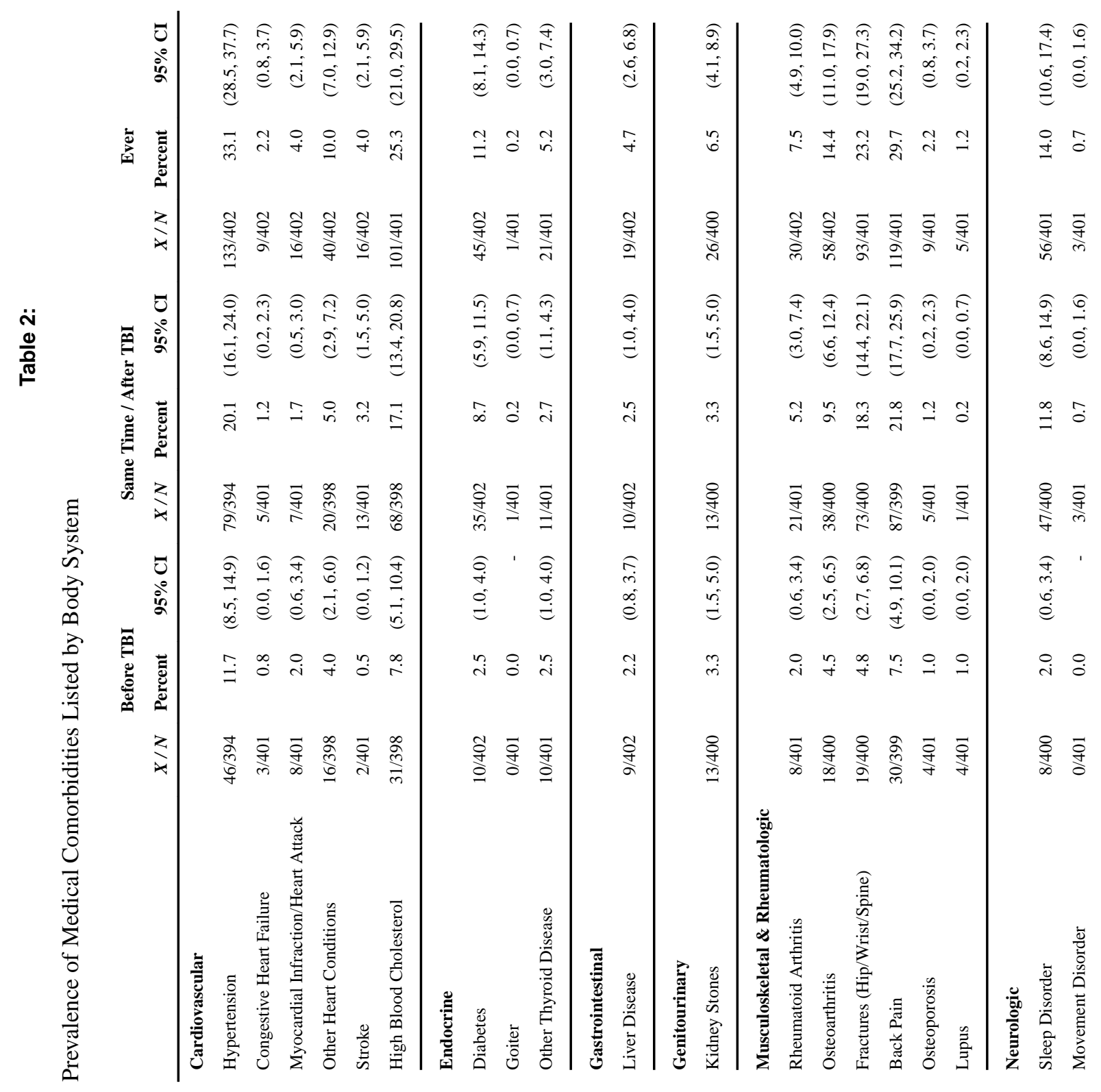

J Head Trauma Rehabil. Author manuscript; available in PMC 2020 July 01. 
Hammond et al.

Page 15

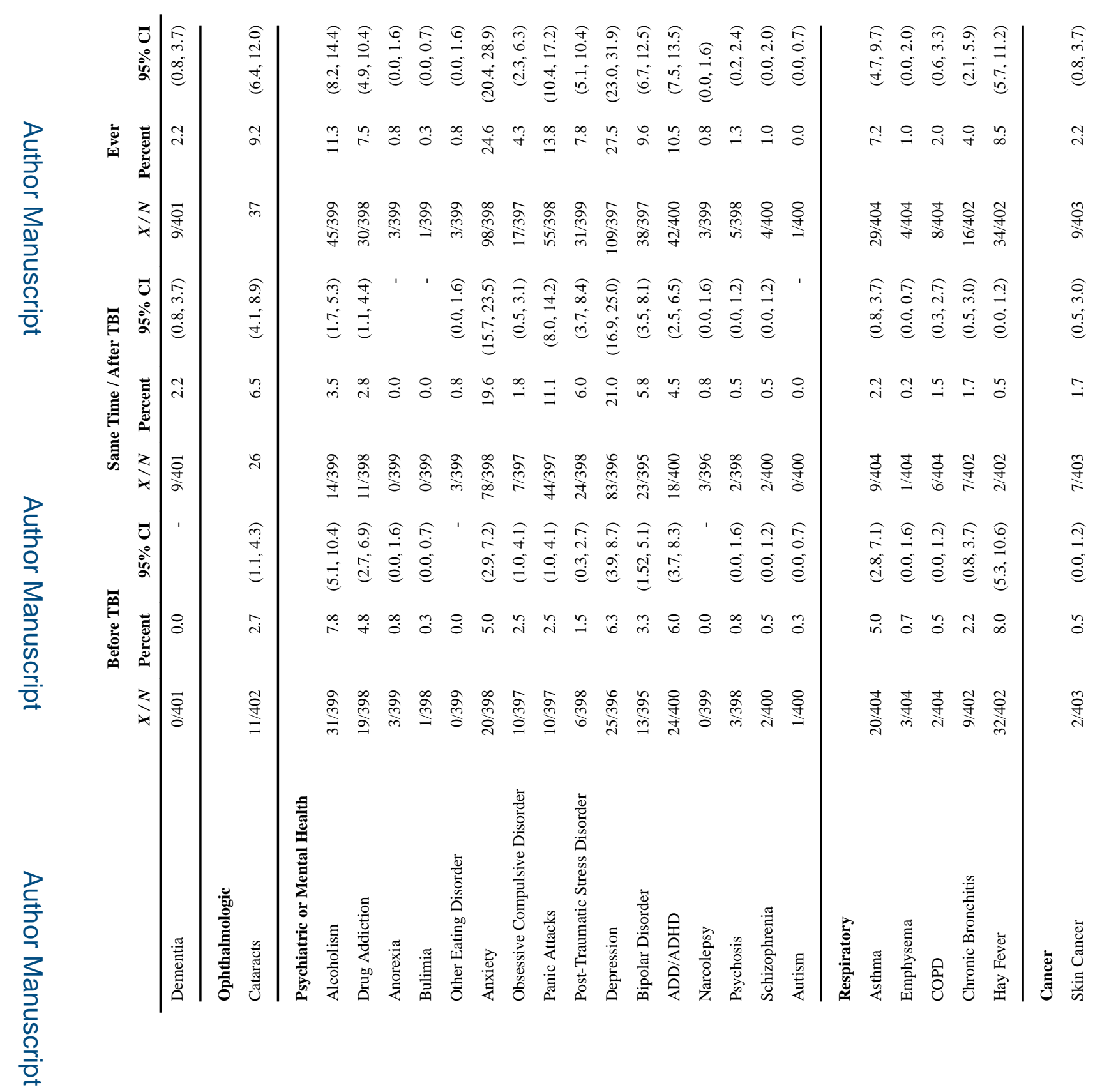

로을

J Head Trauma Rehabil. Author manuscript; available in PMC 2020 July 01. 

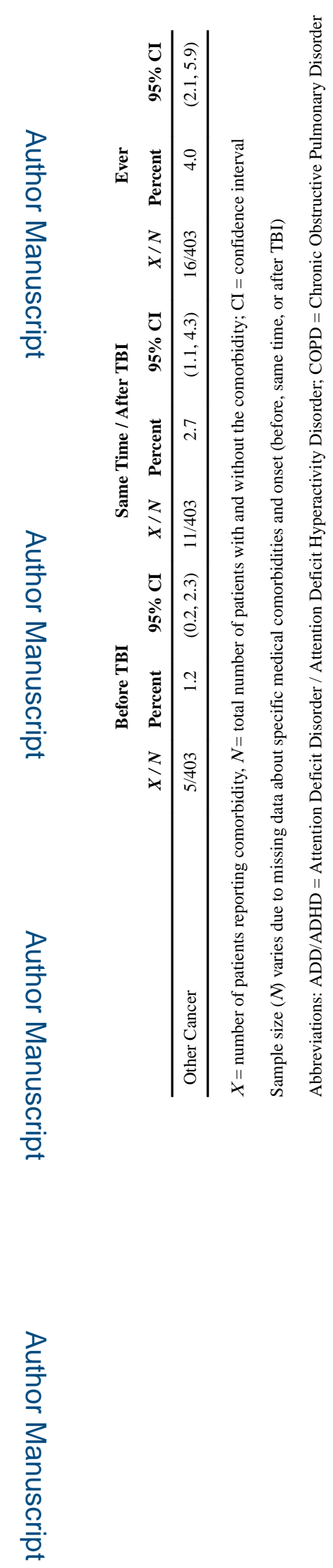
Table 3:

Most Prevalent Medical Comorbidities

\begin{tabular}{|c|c|c|}
\hline $\begin{array}{c}\text { Before TBI } \\
(4.8 \%-11.7 \%)\end{array}$ & $\begin{array}{c}\text { Same Time / After TBI } \\
\quad(8.7 \%-\mathbf{2 1 . 8 \% )}\end{array}$ & $\begin{array}{c}\text { Ever } \\
(11.3 \%-33.1 \%)\end{array}$ \\
\hline Hypertension $11.7 \%$ & Back Pain $21.8 \%$ & Hypertension $33.1 \%$ \\
\hline Hay Fever $8.0 \%$ & Depression $21.0 \%$ & Back Pain $29.7 \%$ \\
\hline High Blood Cholesterol 7.8\% & Hypertension $20.1 \%$ & Depression $27.5 \%$ \\
\hline Alcoholism $7.8 \%$ & Anxiety $19.6 \%$ & High Blood Cholesterol 25.3\% \\
\hline Back Pain $7.5 \%$ & Fractures (Hip/Wrist/Spine) $18.3 \%$ & Anxiety $24.6 \%$ \\
\hline Depression $6.3 \%$ & High Blood Cholesterol $17.1 \%$ & Fractures (Hip/Wrist/Spine) $23.2 \%$ \\
\hline Attention Deficit Disorder 6.0\% & Sleep Disorder $11.8 \%$ & Osteoarthritis $14.4 \%$ \\
\hline Asthma 5.0\% & Panic Attacks $11.1 \%$ & Sleep Disorder $14.0 \%$ \\
\hline Anxiety $5.0 \%$ & Osteoarthritis 9.5\% & Panic Attacks $13.8 \%$ \\
\hline Fractures (Hip/Wrist/Spine) $4.8 \%$ & Diabetes $8.7 \%$ & Alcoholism 11.3\% \\
\hline
\end{tabular}




\section{를}

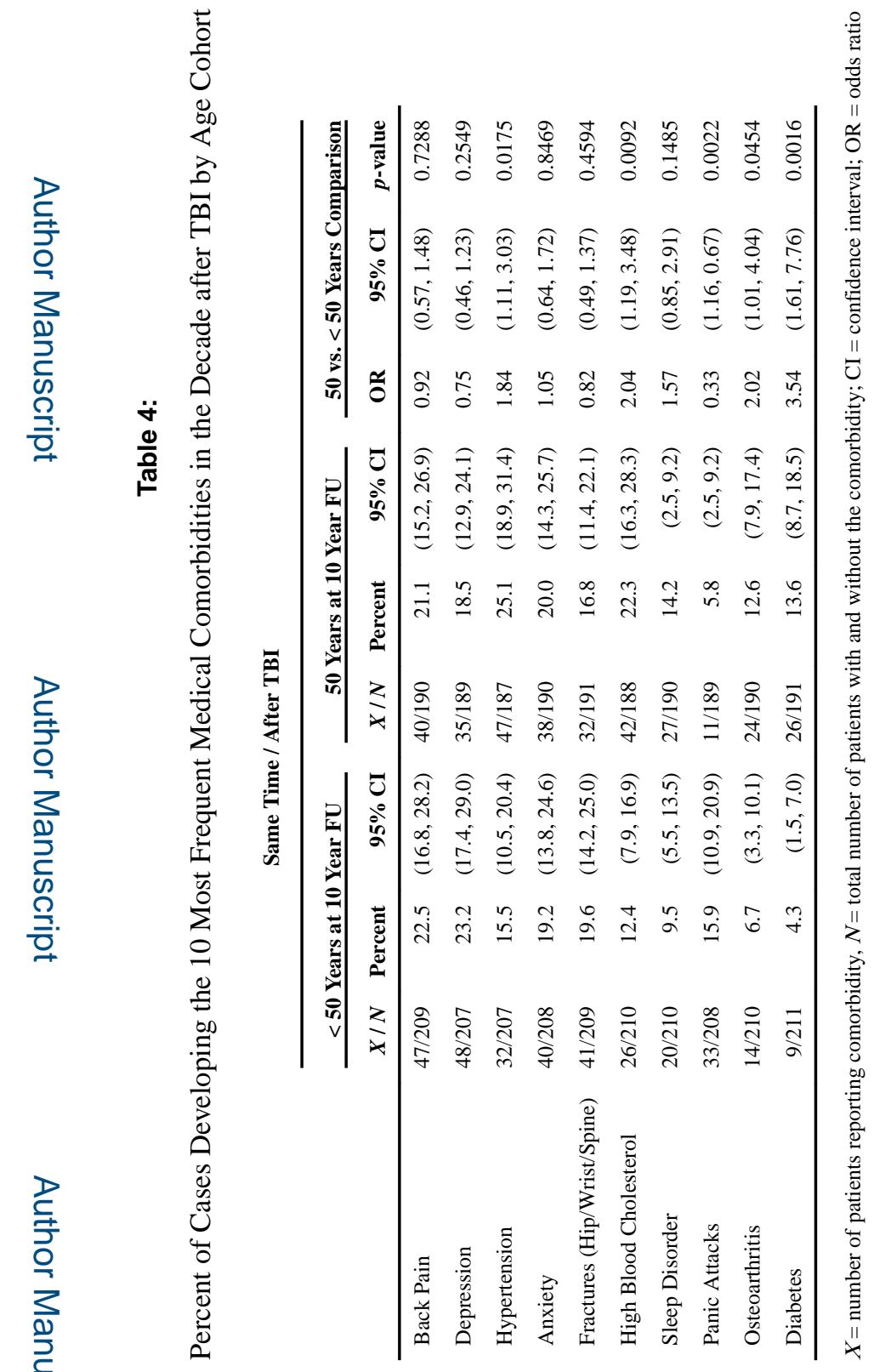

